\title{
A Gendered Imperative: Does Sexual Violence Attract UN Attention in Civil Wars?
}

Michelle Benson

Department of Political Science

SUNY Buffalo
Theodora-Ismene Gizelis

Department of Government

University of Essex

There is increasing awareness that sexual violence is distinct from other aspects of civilian victimization in civil wars. Few studies have examined the independent impact of such violence on responses to civil wars as compared to "traditional" forms of violence. This paper explores whether reports of high levels of rape and sexual violence increase the probability of UN attention to conflicts and calls to action. In so doing, we combine original data on UN Security Council resolutions with data on sexual violence in armed conflict and estimate the impact of sexual violence on UN attention to all civil wars from 1990-2009. We show that the effects of sexual violence on the number and level of UNSC resolutions are shown to be significant even when controlling for other important determinants of UN action. These findings have important implications for understanding how the UN has expanded its view on protecting civilians. 


\section{Introduction}

Attention to sexual violence has skyrocketed since the Bosnian and Rwandan civil wars in the 1990s. Amnesty International, Human Rights Watch, and the State Department all regularly report on systematic abuse and document specific, important episodes of sexual violence. ${ }^{1}$ Human Rights Watch $(2005,7)$ report an example from second Congolese civil war where

...tens of thousands of women and girls were raped or otherwise subjected to sexual violence. Victims whose cases Human Rights Watch documented were as young as three years old. In a number of cases men and boys were also raped or sexually assaulted. The World Health Organization investigated the incidence of rape ... and concluded that some forty thousand persons had been raped.

The United Nations Security Council (UNSC) responded to the conflict in the Democratic Republic of Congo (DRC) by passing a dozen resolutions in the 2003-2004 period. However, based on most prior research on the determinants of UNSC action and resolutions, we would not have expected that the United Nations (UN) to be active towards this conflict, since neither battle deaths nor civilian casualties were particularly high during the 2003-2004 period reported (Fortna 2004, 2008, Beardsley and Schmidt 2012, Hultman 2013, Hultman et al. 2013).

\footnotetext{
${ }^{1}$ We use the definition of sexual violence employed by the Sexual Violence in Armed Conflict (SVAC) dataset, focusing on the forms of violence that make up sexual violence rather than the targets of such violence, directly based on the International Criminal Court (ICC), Elements of Crimes, U.N. Doc. PCNICC/2000/1/Add.2 (2000). Article 8 (2)(e): https://documents-ddsny.un.org/doc/UNDOC/GEN/N00/724/27/PDF/N0072427.pdf?OpenElement, Accessed on 27-05-2018. In summary, sexual violence includes reports of rape, sexual slavery, forced prostitution, forced pregnancy, and forced sterilization/abortion, mutilation and sexual torture. This definition of sexual violence does not exclude the existence of female perpetrators and male victims, both of which are observed in the data. However, the SVAC definition does not include sexual harassment, humiliation or forced nudity (Cohen and Nordås 2013: 7) http://www.sexualviolencedata.org/wp-content/uploads/2013/01/SVAC-coding-manual-10-25-13.pdf, Accessed on 27-05-2018.
} 
What then, explains the high number of UNSC resolutions on the DRC in addition to the traditional attributes held to predict to UN activity? We suggest that a high prevalence of widespread sexual violence can explain UN attention to this and other civil conflicts. Recent work suggests that sexual violence is a distinct type of violence against civilians and can occur at all stages of conflict (Nordås 2011; Cohen, Nordås, and Wood 2014). Given prominence of sexual violence in many conflicts, we expect that reported sexual violence can have an independent effect on promoting UNSC resolutions.

We recognize the deep-rooted structures that may engender sexual violence highlighted by feminist researchers (Enloe 2000; 2002; Meger 2016; Seifert 1994). Sexual violence often reflects deeper forms of hierarchical, violent social structures with implications beyond domestic and international security (MacKenzie 2010; Meger 2016). Our focus here is not to explain the origins of sexual violence but rather examine how the UN responds to the relative magnitude of reported sexual violence. We posit that high prevalence of stated sexual violence has been an important predictor of UNSC resolutions in the postcold war period, even before the "formal recognition" in resolutions addressing the status of women and children with Resolution 1820. It is vitally important to understand the determinants of these resolutions. ${ }^{2}$ UNSC resolutions are precursors for most UN actions and the indicators of global attention and great power willingness to act in specific conflicts. The presence, number and intensity of UNSC resolutions thus indicate global interest in conflicts and the potential for action or intervention in civil wars.

\footnotetext{
${ }^{2}$ While the definition of sexual violence includes both male and female victims, in practice most victims of sexual violence are women and children. Thus, in practice resolutions such as 1820 highlight women and children as victims of sexual violence even though men are also victims of sexual violence in the same conflicts.
} 
We use an original data set on all UNSC resolutions from 1989 to 2014 to examine their relationship to the presence, count, and intensity of sexual violence in UCDP/PRIO conflicts. We find a robust, significant relationship between reports of sexual violence in a conflict and the likelihood that the UNSC will address a civil conflict in a resolution as well as how often. We also find evidence that reports of systematic sexual violence go together with a higher intensity in UNSC response, measured by the type of action called for in resolutions in a conflict-year, as well as the number of resolutions calling for high levels of action (e.g., sanctions or the outside use of force) ${ }^{3}$

Our analysis shows that the impact of sexual violence on resolutions is independent of prior UNSC resolutions and the presence of peacekeeping missions in a conflict as well as other well-established indicators of violence in civil wars. In short, our results indicate that sexual violence is a separate conflict attribute driving the likelihood of UNSC resolutions. These findings have meaningful implications for understanding international conflict intervention and suggest that the norms and motivations of conflict management are perhaps not as limited as suggested in prior literature. Our findings suggest that the likelihood of intervention, which presumes prior UNSC resolutions, is related to a widening understanding of and attention to specific types of violence against civilians and innocents.

\section{Challenging the norm of sexual violence in armed conflicts}

Sexual violence in armed conflict is not a new phenomenon, although awareness about it may be. Enloe (2002) points out that the looting, pillage and rape nexus has been characteristic of violent conflict throughout the history of humankind. Cases of rape by German or Russian forces during WWII or the "rape of Nanking" are by now well

\footnotetext{
${ }^{3}$ Many low-level resolutions are followed by high-level resolutions and almost all UNSC high-level resolutions are followed by actions. There is usually a time gap between SC resolutions and the onset of the action called for by the UNSC. Thus, resolutions reflect attention and intent rather than direct action by the UNSC.
} 
documented, but did not draw much international attention at the time. The violent ninemonth Bangladesh War of Independence in 1971 was the first time that international attention started focusing on rape as a form of political and military strategy independent from other forms of atrocities (Brownmille 1975; Skjelsbaek 2010). Sexual violence and rape were widespread in many of the armed conflicts in Latin American countries such as Guatemala in the 1970s, even though, there was significant variation in the spread of these phenomena (Wood 2006). Yet, sexual violence remained both understudied and under-analyzed as it was not considered equivalent to other forms of violence such as killings and torture often observed in armed conflicts (Meger 2016; Skjelsbaek 2001). Early feminist research made the case that sexual violence was not an inevitable by-product of war, but a reflection of the unequal gender relationships and insecurity experienced by women in their daily lives both in war and peace (Kelly 2000).

It was not until the 1990s when public attention shifted, and mass documentation of rape and sexual violence started with the cases of Bosnia and Rwanda. The shocking reports galvanized public opinion to address sexual violence in wars and persecute the perpetrators (Skjelsbaek 2010). After the international recognition of sexual violence in Bosnia, the international community was prepared to at least document cases of rape and sexual violence. By 1998-1999 when the war in Kosovo took place, sexual violence was part of the international agenda (Skjelsbaek 2010: 22).

What drew attention to rape and sexual violence in the cases of Rwanda and Bosnia was a pattern of violence that became closely intertwined with genocide or ethnic cleansing. Sexual violence became an integral component of warfare where the goal was to destroy the enemy. Researchers have particularly linked sexual violence to conflicts of identity where special cultural value is attached to the women of the enemy group and violence was gender specific with a cultural function to harm the collective identity of the group (Bos 2006; 
Seifert 2016). Sexual violence in conflicts such as Sierra Leone and the DRC in the 2000s led to the conceptualization of sexual violence as a strategic choice and a "weapon of war" (Cohen 2013; Wood 2006; 2009).

Feminist scholars, have argued against simplistic definitions. They problematized the concepts of security and sexual violence as applied in most of the international security literature (Baaz and Stern 2008, 2010, 2013; Meger 2016). Scholars like Skjelsbaek (2010) and Seifert (1994) argued that sexual violence has distinct characteristics from other types of violence observed in wars, because it reflects fundamental power dynamics rooted in social norms and institutions both in war and beyond war. Earlier feminist literature conceptualized sexual violence as being embedded in the militarization of societies and gender unequal relationships (Enloe 2000; Seifert 1994).

Recent research has focused on the causes of sexual violence in armed conflict within two lines of inquiry - either as an opportunistic by-product of war or as a strategic weapon of war (Meger 2016). However, scholars including Eisenstein (2007), Mackenzie (2010), Meger (2016), and Whitworth (2004) have challenged this work for moving away from early feminist discourse by adopting narrow concepts of security and sexual violence. Adopting formulaic and narrow concepts, usually emphasizing rape, researchers sensationalize sexual violence. The narrative of rape as a weapon of war creates hierarchies of crime severity leading to the securitization of sexual violence in research, advocacy, and policy. As a result, "gender" and sexual violence become hollow concepts depleted from their political dimension (Meger 2016: 150). The fetishization of sexual violence separates the act from its root causes in unequal gender relationships, while the securitization process frames sexual violence as an abnormal and existential threat to social norms and family life (Mackenzie 2010: 217). 
Mackenzie (2010) uses unstructured interviews and the court case archives by the Government of Sierra Leone and the UN against the major warring factions in the conflict of Sierra Leone and Charles Taylor to identify multiple forms of oppression and abuse. All these forms, from forced marriage and pregnancy to slavery and abduction, were interlinked with sexual violence and rape, and ultimately the structure of the family unit. As a result, the stigma, marginalization, and suffering of the victims and their families continued after the end of the conflict reproducing unequal and oppressive power dynamics outside the war time frame (Mackenzie 2010).

The motivations of perpetrators who engage in sexual violence and the structures that enable them to engage in sexual violence do not alter the fact that sexual violence during armed conflict has an impact on security and peace empirically distinct from other forms of violence (Cohen 2013; Hoover Green 2011; Skjelsbaek 2001: 80; Wood 2009). Thus, many actors in global politics, such as the UN and NGOs, categorize sexual violence as a matter of security and peace. As such it fully warrants attention and potentially a security response by the international community (Anderson 2010: 246-247). ${ }^{4}$

\section{UN Security Council and protection from sexual violence}

The complexity of sexual violence in armed conflict leads to questions regarding the specific responses of international organizations and the UN to often emotive reports of such basic human rights violations. In other words, is sexual violence a "characteristic" of violent armed conflicts that influences the willingness of the UN Security Council to pay attention to conflicts involving sexual violence? Prior research on the decision-making process of the

\footnotetext{
${ }^{4}$ It is important to note that Sexual violence does not always coincide with other forms of atrocities. For example, in Sierra Leone, sexual violence comes before higher levels of civilian battle deaths while in the DRC after 1998, battle deaths seem to precede higher levels of sexual violence and reported rates of sexual violence are elevated even when civilian deaths and battle deaths are not. In short, a majority of conflicts exhibit a pattern where sexual violence is relatively independent from other forms of violence in civil wars.
} 
UN Security Council (SC) has primarily focused on narrowly defined security and strategic aims of the country members of the Security Council, especially the permanent five (P5) members. The common assumption is that the UNSC responds only to cases of economic and military strategic interest of the P5, ignoring conflicts and crises that do not fit these criteria, especially in mandating peacekeeping missions (Stojek and Tir 2015).

Studies such as Beardsley and Schmidt (2012) showed that national interest is not the only one that determines whether the UN Security Council will sanction the involvement of UN in a crisis. Other researchers (Hultman, Kathman, and Shannon 2013) suggest that the Security Council responds to humanitarian crises and threats against civilians. Meanwhile Benson and Kathman (2014), by examining UNSC resolutions, argue that the Security Council takes decisions for or against specific conflict actors based on aggregate Security Council member preferences. In other words, it is not just the country characteristics that motivate the SC to sanction a UN intervention, but also the conflict dynamics.

In 2000, it became clear that the UN Security Council had come to accept that sexual violence is a specific form of violent behavior that threatens security and thus deserves attention independently from other forms of violence against civilians. The formalization of this attitude began with United Nations Security Council Resolution 1325 (2000) and was solidified by UNSCR 1820 (2008). The attention on sexual violence preceded similar trends in protecting civilians from violence in intrastate conflicts galvanized with the Responsibility to Protect (R2P) in 2005 (Bellamy 2009; Evans and Sahnoun 2002; Stahn 2007).

The concurrence of several UNSC resolutions and R2P suggests a shift in international law to address crimes against humanity and mass atrocities. In all, the collected activism could generate a stronger sense of moral responsibility to protect women and girls from sexual violence, including changing the international legal landscape. The International Criminal Tribunals for Yugoslavia (ICTY 1993) and Rwanda (ICTR 1994) recognized sexual 
violence in armed conflict as a war crime and a crime against humanity (Chun and Skjelsbæk 2010). It was UNSCR 1325 that formally demarcated sexual violence in conflict as a threat to peace and security. ${ }^{5}$

The numerous follow-up resolutions to UNSCR 1325 in the UN's Women Peace and Security Agenda have become increasingly detailed in their provisions. A large amount of Security Council statements exists where Secretary General reports on events and implementation policies have been formulated to translate the emerging norm on the role of gender in peace and security into action. Attention to these issues has also spread to decisions and policies in many regional organizations and states. While some resolutions specifically refer to UNSCR 1325 (e.g., resolution 1565 addressing the DRC conflict in 2004), most resolutions on civil conflicts do not and many UNSC resolutions fail to address sexual violence when it is present (e.g., resolution 1555 addressing the DRC conflict in 2004). Indeed, it took eight years after the passage of UNSCR 1325 until Security Council resolution 1820 (2008) became the first resolution to exclusively address sexual violence in armed conflict.

A distribution of all the UNSC resolutions mentioning violence against women and children is presented in Appendix (see Figure A1). As is illustrated, the UN did not begin to

\footnotetext{
${ }^{5}$ The resolution was the result of a long political and historical process. It had its roots in the adoption of the UN Charter in 1945. From the "UN Decade for Women" (1975-85) women's situation and gender equality became increasingly connected to questions of international peace and security. The development was further enforced in the "Beijing Declaration and Plan of Action", adopted in 1995 at the UN Decade for Women. When UNSCR 1325 was finally adopted in October 2000, it rested on a substantive policy development involving member states - such as Bangladesh, Namibia, Canada, and Jamaica - women's civil society organizations from areas affected by armed conflict (for example, Guatemala and Somalia), and UN actors inside the UN system. The interchange between international organizations, member states, NGOs and civil society has remained a key component of the policy work on gender in relation to international peace and security; a work that has resulted in a number of follow-up resolutions: UNSCR 1820(2008), 1888(2009), 1889(2009), 1960(2010), 2106(2014) and 2122 (2014) (for an overview of this process, see, for example, Binder, Lukas, and Schweiger 2008; Carey 2001; Cohn, Kinsella, and Gibbings 2004; Krause 2015; Olsson 2000; Shepherd 2008; Tryggestad 2009). The ongoing developments related to the role of gender for peace and security also influenced the Department of Peacekeeping Operations, required to transform the normative developments into practical work (Olsson and Gizelis 2015).
} 
formally address violence against women and children in its resolutions until the early 2000's. Indeed, the UN has a history of under-reporting the nature and extent of atrocities within its resolutions and even refusing to explicitly name specific aggressors in conflicts (Benson and Kathman 2014). Does this lack of specific mention of atrocities (i.e., sexual violence, genocide, civilian massacres) in a UNSC resolution mean that the UN is not aware of or paying attention to important conflict attributes within a civil war?

We argue strongly that this is not the case. While the UN does often not respond appropriately (or at all) to the majority of civil or international conflicts in resolutions (Benson and Satana 2008), it is generally accepted that when the UNSC does pass a resolution, it is based upon a documented disturbance to the security of populations, governments, or regions. Indeed, much of the literature on UN actions or the use of force does not suggest an explicit link between $\mathrm{UN}$ actions and UN recognition of conflict attributes (e.g., Beardsley and Schmidt's 2012 work on International Crises). To obtain consensus between P5 members, UN resolutions are often purposely vague in assigning blame or in mentioning specific events. The delayed and often limited mention of sexual violence or lack of referral to sexual violence resolutions by the Security Council does not mean that the UN is blind or indifferent to the phenomenon. Just as every UNSC resolution does not mention all atrocities in conflicts, the same may be said for the crime of sexual violence in civil war (Johansson and Hultman n.d.).

Given that the language of resolutions cannot be used to determine attention to specific atrocities, we must turn to the empirical association between the existence of UNSC resolutions on a specific conflict and the conflict's attributes (as has been suggested by the above literature). If, for example, there is a statistically significant relationship between civilian deaths, conflict intensity or sexual violence and the presence or intensity of UNSC resolutions, it suggests that the $\mathrm{UN}$ is focused on addressing such atrocities within the context 
of civil wars. Indeed, just such an approach has been employed by much of the quantitative literature on UN resolutions and UN peacekeeping, discussed immediately below. In the Sierra Leone, reporting of high prevalence of sexual violence precedes the initiation of a UN mission within the country (Sierra Leone). Similarly, in the case of DRC increasing levels of sexual violence are associated with resolutions mandating UN missions to protect vulnerable civilians from physical harm, such as Resolutions 1291 (2000), 1565 (2004), and 1856 (2008) that expanded the mandate and the size of United Nations Organization Mission in the Democratic Republic of the Congo (MONUC).

\section{A theoretical approach to factors influencing $\mathrm{UN}$ attention to civil wars}

What then, determines whether the UN passes resolutions on specific armed conflicts? Are the national interests of the P-5 in Security Council the deciding factor for UN action as often assumed (Anderson 2000; Carter 2007; Gibbs 1997; Stojek \& Tir 2015)? The literature on UN interventions tries to provide answers to these questions by focusing on the characteristics of the conflict. Gilligan and Stedman (2003: 38) showed that conflict severity, measured in terms of causalities, as the key factor for intervention. Fortna and de Jonge Oudraat also suggest that UN tends to intervene in more severe conflicts (Fortna 2004; 2008; de Jonge Oudraat 1996). Beardsley and Schmidt (2012) show that although the national interests of the five permanent members of the Security Council influence and constrain the ability of the UN to act in international crises, the severity of conflicts is a more important predictor of UN intervention. Thus, the UN abides by the principle of the responsibility to protect civilians and intervenes mainly in so-called "hard cases" (see also Hultman 2013; Hultman, Kathman, and Shannon 2013; Ruggeri, Dorussen, and Gizelis 2016). Benson and Kathman (2014) also show that the UN Security Council's decisions are driven not only by the intensity of the conflict, as well as the national interests of the Security Council members, but also by links to local actors and a vested interest in the conflict dynamics. Their study 
suggests that the Security Council members might take a more nuanced and intricate approach to the unfolding of conflicts that is often assumed.

Within its institutional format, the UN has the agency to address specific issues of civilian concern and security through the organ of the Security Council. Action within the UNSC is largely manifested through the passing of resolutions. UN Security Council Resolutions are legally binding documents that signal the resolve of the Council to pay attention on specific issues and eventually take action. Furthermore, UNSC resolutions require consensus to be legally binding. In practical terms, for a resolution to pass, it must obtain nine Security Council votes. This means the resolution must be supported (or not actively opposed) by the Permanent Five members of the Security Council and have support from at least four (out of ten) non-permanent members.

While the composition of the non-permanent members varies, there is evidence that financial aid by the US, Germany and the UN itself is correlated with the tenure of a nonrotating member (Kuziemeke and Werker 2006). A possible policy implication of the correlation between aid and the tenure of non-permanent members is regardless of the composition of the Security Council there are enough incentives for non-permanent members to converge on specific policy agendas. This convergence of preferences is a possible explanation of why many resolutions successfully pass and very few fail (Kuziemeke and Werker 2006).

Resolutions thus represent the cohesion of preferences in the UNSC among the key agenda setters and indicate a general agreement among the P5 to address a conflict or issues pertained to security within that conflict. We expect that if sexual violence is perceived a threat to security and a political priority, then the UNSC should be equally motivated to pass a resolution in conflicts when there have been reports high levels of such abuses. While not 
all resolutions lead to action, the passage of any resolution is a clear indication that the UNSC has focused on a conflict.

These resolutions do not need to name a specific factor (e.g. violence against civilians, high levels of battle deaths, etc.) to exert influence or reflect the political will of the UN Security Council. Yet, we still expect that if the many conflict factors identified in the literature matter, then the UNSC could signal its willingness to address specific conflicts through the mechanism of passing resolutions. Empirically, we posit that if sexual violence is viewed as a salient conflict factor by the UN, there should be a higher probability of a UNSC resolution on an armed conflict after reports of sexual violence independent from other factors that might characterize and draw attention to the conflict. In addition, a higher number of UNSC resolutions passed on a conflict suggests an even greater UNSC attention to, and focus on, an armed conflict. We summarize the theoretical discussion above in the following hypotheses:

H1: Higher levels of sexual violence in an armed conflict are associated with a higher probability of a UNSC resolution (net of any other characteristics) in the conflict-year.

H2: Higher levels of sexual violence in an armed conflict are associated with larger number of UNSC resolutions in a conflict-year.

Finally, we posit that if the UNSC considers sexual violence to be an important conflict attribute, then we would expect a more robust response within the resolutions themselves. As such, we suggest that a higher prevalence of sexual violence should lead to higher levels of suggested UN action within the resolutions (e.g., peacekeeping vs. diplomacy) and a higher frequency of high-level resolutions within a conflict-year.

H3: Higher levels of sexual violence in a conflict are associated with a higher level of proscribed action in the UNSC resolutions in a conflict-year. 
H4: Higher levels of sexual violence in a conflict are associated with a higher number of resolutions with a high level of recommended action in the UNSC resolutions in a conflictyear.

\section{Research Design and Data}

In estimating the relationship between UNSC resolutions and reports on the prevalence of sexual violence, we examine all intrastate conflict-years included in the UCDP/PRIO dataset from 1990 until 2009.

\section{Dependent Variables}

We employ four dependent variables to test the four propositions. These four UNSC resolution variables were coded as part of an original dataset on UN Security Council Resolutions that pairs UCPD/PRIO armed conflicts with their respective United National Security Council resolutions. ${ }^{6}$ Both the target and level of action for all resolutions on intrastate conflicts are coded for the post-cold war period. Resolutions are coded to conflicts based on the specific mention of the conflict or conflict actors within a resolution. When multiple conflicts are implicitly referred to in a UNSC resolution, the dataset codes the resolution as an "umbrella" resolution pertaining to multiple conflicts. The bivariate and count variables used here include both the specific and umbrella UNSC resolutions.

The distribution of resolutions across time in the 1990-2014 period has been relatively constant. However, note that our empirical results are limited to the 1990-2009 period due to independent variable limitations. During this period, there is no discernible pattern for the number of resolutions the UN passed on civil conflicts in a particular year as illustrated in

\footnotetext{
${ }^{6}$ UCDP uses a very specific definition of violent armed conflict that excludes forms of political violence, e.g. riots. Feminist research has challenged concepts used in mainstream security literature (Meintjes, Turshen, and Pillay 2001; Sjoberg 2013). Nevertheless, this paper primarily contributes to the empirical research on peacekeeping. Thus, we benchmark our analysis to the extant research using the same measurements and methods.
} 
Appendix A2. We also think it important to note that conflicts receiving high-levels of attention from the UN via UNSC resolutions varies substantially from year-to year.

The first of our dependent variables is the presence of a UNSC resolution in a conflict year where $1=$ the presences of a UNSC resolution, 0 otherwise. Our second dependent variable is the count of UNSC resolutions in a conflict/year (as exhibited in Figure 3). This variable ranges from 0 resolutions per year (e.g., Mali, Senegal) to 14 resolutions per year (e.g., Bosnia-Herzegovina in 1993). As with the presence of UNSC resolutions, we expect that severe sexual violence should be associated with sustained UNSC attention to a conflict during the year.

To code our third dependent variable, the level of action proposed in a UNSC resolution, we code the text of all resolutions relating to UCDP intra-state conflicts. The level of action is coded on a six-point scale where:

$0=$ no resolution

$1=$ resolution pertaining to conflict (no request, action by UN)

$2=$ demand towards the government, rebels or no target of demand

$3=$ diplomacy (establishment of mediation, good offices, or committee)

$4=$ sanction or siege

$5=$ approval or extension (time or troops) of the use of force by an outside actor (state or IGO)

$6=$ formation or extension (time or troops) of a UN peacekeeping mission

Finally, we examine the count of high-level actions within a conflict-year. This variable best allows us to obtain best ascertain the level of high-intensity responses regarding civil conflicts. This dependent variable is counts the number of resolutions that score a 4, 5, or 6 on the level of action scale above. The variable ranges from 0 to 11 in the conflict-year (e.g., 10 for Angola in 1998, and 11 for Bosnia-Herzegovina in 1993). Independent Variables

Our primary independent variables measure the reported prevalence of sexual violence in UCDP conflicts (Cohen and Nordås 2014). Cohen and Nordås’ data set includes variables on the prevalence of sexual violence in civil conflicts. The data are based on the 
three most common datasets in quantitative human rights literature: The US State Department annual reports; Human Right Watch reports; and Amnesty International annual and systematic reports (Cohen and Nordås 2013). ${ }^{7}$ The SVAC dataset measures the prevalence of sexual violence as an estimate of the reported magnitude of sexual violence by Amnesty International, Human Rights Watch, and the State Department. The definitions in SVAC largely reflect the concepts and normative assumptions of international agencies of what constitutes "sexual violence". Such concepts partly reflect the political nature of sexual violence and delineate who can be included as a victim of sexual violence and who is excluded (Zalewski et al 2018). By adopting the SVAC definitions and data we can compare our key findings to other empirical studies on UN response to conflicts.

These three variables are measured on an ordinal scale where

$0=$ no reported sexual violence

$1=$ some: reports, isolated reports, or there continued to be reports of sexual violence

$2=$ Several/many: widespread: common, commonplace, extensive, frequent, often, persistent, recurring, a pattern, a common pattern, or a spree

$3=$ Massive: innumerable, or systematic

Following Beardsley and Schmidt's (2012) approach to crisis severity and duration in predicting UN resolutions and responses to international conflicts, we also employ predictor variables that are contemporaneous with our dependent variables. Nevertheless, we have run a series of robustness checks with lagged variables (and different combinations of lagged variables) to ensure that our findings are robust to a variety of variable specifications.

A distribution of the State Department reports of sexual violence over time illustrates that there have been consistent reports of all levels of sexual violence over the period of the study (see Appendix Figure A3). Virtually identical distributions are found with the Amnesty

\footnotetext{
${ }^{7}$ Their codebook provides detailed information regarding the sources, coding rules, and data limitations. In general, the US State Department reports are the most comprehensive, followed by Amnesty International. Human Rights Watch has more gaps in annual reports than the other two datasets. For additional discussion of these variables and the definition of sexual violence, please see footnote 1 .
} 
International and Human Rights Watch variables over time. While our dependent variable ranges from 1989 until 2014, the use of Sexual Violence variables limits the time period to the 1990-2009 period.

\section{Control Variables}

To account for additional humanitarian concerns and the UN's responsibility to protect noncombatants, we control for the total number of civilian deaths in a conflict-year, (in 10,000s) as coded by the UCDP GED Conflict Polygon Dataset (Croicu, and Sundberg 2012). The protection of civilians has become a core principal espoused by Secretaries General. Thus, one might expect rising civilian deaths to be associated with a greater likelihood of attention from the UNSC and an increased number of resolutions in a conflictyear. Importantly, civilian battle deaths are relatively independent from the Human Rights Watch, State Department, and Amnesty International measures of sexual violence (correlations are $\mathrm{r}=0.17, \mathrm{r}=0.08$, and $\mathrm{r}=0.11$ respectively). Thus, the presence of high levels of civilian casualties is not a strong determinant of the presence of sexual violence in civilian conflicts. While one-sided violence against civilians is an important control variable in our analyses, it is important to note that inclusion of the Civilian Deaths variables reduces the number of observations from a maximum of $n=1040$ to a maximum of $n=708$ (dependent upon the Sexual Violence variable employed). As such, we run each of our models with the inclusion of the Civilian Deaths variable and without this variable.

We further control for the UCDP's best estimate of Battle Deaths (Lacina and Gleditsch, 2005) in 10,000s a conflict-year. One would expect that higher levels of casualties would garner increased attention from the UN. The battle death variable correlates between $r=0.06$ and $r=0.08$ with the prevalence of sexual violence variables, above. The intensity of battle deaths variable, likewise, is largely empirically distinct from our two measures of sexual violence. As with the Civilian Deaths variable above, the inclusion of Battle Deaths 
dramatically reduces the number of available observations. ${ }^{8}$ Battle Deaths (along with Civilian Violence) is therefore included in half of our estimations (Tables 1, 3, 5 and 6) and excluded from half of the tables (Tables 2, 4, A1, and A2) to allow for an examination of the impact of Sexual Violence on UNSC resolutions and their intensity for as many conflict-year observations as possible.

In addition, we include a variable for the post-Resolution 1325 period. This resolution was unanimously passed by all 15 UNSC members on October 31, 2000 and specifically addressed the issue of sexual violence in international and civil conflict. As noted above, we would expect the UNSC to pay more attention to conflicts with high levels of sexual violence but need to ensure that this attention is not wholly driven by the recognition of sexual violence as a valid conflict attribute in the post-UNSC 1325 era. This variable is thus coded as 1 from 2001, onward and 0 otherwise. We further include a lagged dummy variable for the presence of UN peacekeeping personnel, observers or police (Kathman 2013). The prior establishment of a UN mission of any size, we recognize, might increase the likelihood of the presence of resolutions and/or high-level resolutions within a conflict year.

We similarly control for a measure of the overall Conflict Duration and intensity of the conflict. Cumulative Intensity takes a value of 1 when a civil conflict has crossed the 1,000 battle- deaths threshold (UCDP). ${ }^{9}$ Given the UNSC's mandate to help ensure regional peace and stability as well as parochial P5 interests, we suggest it is important to control for state attributes that might push the UN to be more attentive to conflicts. As such we include

\footnotetext{
8 The inclusion of the battle deaths and one-sided violence variables decrease the number of observations by 333 and 195, respectively.

9 The intensity variable has a correlation coefficient of 0.17 with the Amnesty International measure of sexual violence, $r=0.19$ for Human Rights watch measure and $r=0.25$ for the State Department measure of sexual violence. The UN Troops and Lag of Resolutions variables correlate at $r=0.26$.
} 
controls for state's population size (in 10,000's) and Real GDP per capita (in $\$ 100,000$ ) (both from Gleditsch 2002), Permanent Five colony status ( $1=$ former colony, else $=0)$ is an additional important control for possible links, in particular trade relationships, between former colonies and members of the P5 group. As noted by Berthou and Ehrhart (2017), preestablished colonial ties can significantly affect trade networks with both the former colonial powers as well as the former colonizer's neighbours. Finally, we include a lagged dependent variable for the presence of past UNSC resolutions because past attention to a conflict by the UN should increase the likelihood of current attention and the likelihood of recommending increasingly intense action in a conflict.

\section{Analysis and Results}

Since we employ four different dependent variables, one binary, two-counts and one ordinal, we use logit, negative binomial regression, and ordinal logit to estimate our models. We present the coefficients in the tables below with robust standard errors in parentheses. Two tailed significance levels for coefficients are indicated as superscripts next to the coefficients.

Table 1 presents our results for the presence of a UNSC resolution in a civil conflictyear with the inclusion of the Civilian Deaths and Battle Death variables. Table 2 provides a model without the inclusion of Civilian Deaths and Battle-Related Deaths. The Civilian Deaths variable, as expected, has a significant, positive relationship with the presence of UNSC resolutions but it not statistically significant in either of the four models. In Table 1, the State Department measure of Sexual Violence is statistically significant but the Human Rights Watch and Amnesty International measures fail to obtain significance. When a more complete number of conflict-years is analysed in Table 2, all three Prevalence of Sexual Violence measures have a significant impact on the presence of UNSC resolutions in a conflict year. Likewise, in Table 2 (when the models are estimated with a larger number of 
observations), Cumulative Conflict Intensity is generally shown to have a positive, significant impact on the presence of resolutions. Not surprisingly, the presence of a UNSC resolution in the prior year increases the likelihood of a current resolution as does the established presence of UN personnel in the civil-conflict. These three variables have a similarly positive and significant effect on UNSC resolutions in the following six tables presented below.

Importantly, in Table 2, the lower values for the BICs and AICs (presented at the bottom of the tables) suggest that the models including the Prevalence of Sexual Violence variables (Models 2, 3, and 4) are preferable to the base model (i.e., Model 1). The conclusions from the BICs and AICs are identical across all further estimations in the manuscript. Jointly, and across all but two of our 28 models presented in the manuscript, 
Table 1

\begin{tabular}{|c|c|c|c|c|}
\hline \multicolumn{5}{|c|}{$\begin{array}{l}\text { Logit: Presence of UNSC Resolutions in a Conflict-Year } \\
\qquad 1990-2009\end{array}$} \\
\hline \multirow{3}{*}{$\begin{array}{l}\text { Sexual Violence } \\
\text { State Dept }\end{array}$} & Model 1 & Model 2 & Model 3 & Model 4 \\
\hline & & $0.556^{*}$ & & \\
\hline & & $(0.273)$ & & \\
\hline \multirow{2}{*}{$\begin{array}{l}\text { Sexual Violence } \\
\text { HRW }\end{array}$} & & & 0.503 & \\
\hline & & & $(0.315)$ & \\
\hline \multirow{2}{*}{$\begin{array}{l}\text { Sexual Violence } \\
\text { Amnesty Int }\end{array}$} & & & & 0.299 \\
\hline & & & & $(0.227)$ \\
\hline \multirow{2}{*}{ Civilian Deaths } & 0.265 & 0.315 & 0.196 & 0.287 \\
\hline & $(0.273)$ & $(0.265)$ & $(0.238)$ & $(0.272)$ \\
\hline \multirow[t]{2}{*}{ Battle Deaths } & 0.705 & 0.693 & $0.813^{+}$ & 0.703 \\
\hline & $(0.483)$ & $(0.545)$ & $(0.480)$ & $(0.494)$ \\
\hline \multirow{2}{*}{ UN Personnel $t_{t-1}$} & $2.034^{* * *}$ & $2.113^{* * *}$ & $2.042^{* * *}$ & $2.061^{* * *}$ \\
\hline & $(0.426)$ & $(0.425)$ & $(0.416)$ & $(0.423)$ \\
\hline \multirow{2}{*}{$\begin{array}{l}\text { Cumulative } \\
\text { Intensity }\end{array}$} & 0.603 & 0.404 & 0.194 & 0.524 \\
\hline & $(0.479)$ & $(0.504)$ & $(0.529)$ & $(0.487)$ \\
\hline \multirow{2}{*}{ Conflict Duration ${ }_{t-1}$} & -0.0155 & -0.0136 & -0.0094 & -0.0151 \\
\hline & $(0.0172)$ & $(0.017)$ & $(0.0176)$ & $(0.0172)$ \\
\hline \multirow{2}{*}{ Resolution 1325} & $0.828^{+}$ & 0.632 & 0.587 & 0.729 \\
\hline & $(0.514)$ & $(0.483)$ & $(0.483)$ & $(0.466)$ \\
\hline \multirow{2}{*}{ P5 Colony } & $-0.616^{+}$ & $-0.729 *$ & -0.410 & $-0.608^{+}$ \\
\hline & $(0.359)$ & $(0.367)$ & $(0.386)$ & $(0.362)$ \\
\hline \multirow{2}{*}{ rGDPpc } & -0.114 & -0.0615 & -0.0675 & -0.0771 \\
\hline & $(0.146)$ & $(0.112)$ & $(0.123)$ & $(0.132)$ \\
\hline \multirow{2}{*}{ Population } & $-0.324^{+}$ & -0.328 & -0.317 & -0.325 \\
\hline & $(0.196)$ & $(0.221)$ & $(0.207)$ & $(0.202)$ \\
\hline \multirow{2}{*}{ Resolution $_{t-1}$} & $3.468^{* * *}$ & $3.524^{* * *}$ & $3.427^{* * *}$ & $3.492^{* * *}$ \\
\hline & $(0.413)$ & $(0.471)$ & $(0.469)$ & $(0.424)$ \\
\hline \multirow[t]{2}{*}{ Constant } & $-2.377^{* * *}$ & $-2.527^{* *}$ & $-2.527^{*}$ & $-2.446^{* * *}$ \\
\hline & $(0.438)$ & $(0.481)$ & $(0.522)$ & $(0.447)$ \\
\hline$N$ & 715 & 707 & 627 & 708 \\
\hline Pseudo. $R^{2}$ & 0.612 & 0.620 & 0.630 & 0.614 \\
\hline Chi Square & $147.64 * * *$ & $154.86^{* * *}$ & $127.58 * * *$ & $145.13 * * *$ \\
\hline 11 & -126.05 & -122.81 & -109.49 & -125.12 \\
\hline AIC & 274.1 & 269.6 & 243.0 & 274.2 \\
\hline BIC & 324.39 & 324.36 & 296.3 & 329.0 \\
\hline
\end{tabular}


Table 2

Logit: Presence of UNSC Resolutions in a Conflict-Year 1990-2009

\begin{tabular}{|c|c|c|c|c|}
\hline & Model 1 & Model 2 & Model 3 & Model 4 \\
\hline \multirow{2}{*}{$\begin{array}{l}\text { Sexual Violence } \\
\text { State Dept }\end{array}$} & & $0.609^{* *}$ & & \\
\hline & & $(0.191)$ & & \\
\hline \multirow{2}{*}{$\begin{array}{l}\text { Sexual Violence } \\
\text { HRW }\end{array}$} & & & $0.640^{*}$ & \\
\hline & & & $(0.292)$ & \\
\hline \multirow{2}{*}{$\begin{array}{l}\text { Sexual Violence } \\
\text { Amnesty Int }\end{array}$} & & & & $0.487^{*}$ \\
\hline & & & & $(0.198)$ \\
\hline \multirow{2}{*}{ UN Personnel ${ }_{t-1}$} & $1.475^{* * *}$ & $1.782^{* * *}$ & $1.644^{* * *}$ & $1.765^{\text {*** }}$ \\
\hline & $(0.268)$ & $(0.337)$ & $(0.328)$ & $(0.332)$ \\
\hline \multirow{2}{*}{$\begin{array}{l}\text { Cumulative } \\
\text { Intensity }\end{array}$} & $0.990^{* * *}$ & $0.841^{*}$ & 0.669 & $0.872^{*}$ \\
\hline & $(0.270)$ & $(0.370)$ & $(0.369)$ & $(0.363)$ \\
\hline \multirow{2}{*}{$\begin{array}{l}\text { Conflict Duration } \\
\text { t-1 }\end{array}$} & -0.0139 & -0.00806 & -0.00683 & -0.00833 \\
\hline & $(0.0115)$ & $(0.0149)$ & $(0.0151)$ & $(0.0153)$ \\
\hline \multirow{2}{*}{ Resolution 1325} & $1.206^{* * * *}$ & $0.738^{*}$ & 0.680 & $0.806^{*}$ \\
\hline & $(0.300)$ & $(0.368)$ & $(0.370)$ & $(0.358)$ \\
\hline \multirow{2}{*}{ P5 Colony } & $-0.540^{*}$ & $-0.648^{*}$ & -0.338 & -0.498 \\
\hline & $(0.266)$ & $(0.309)$ & $(0.317)$ & $(0.307)$ \\
\hline \multirow{2}{*}{ rGDPpc } & $-0.358^{* *}$ & -0.170 & -0.194 & -0.186 \\
\hline & $(0.134)$ & $(0.181)$ & $(0.200)$ & $(0.202)$ \\
\hline \multirow{2}{*}{ Population } & -0.118 & -0.293 & -0.278 & -0.283 \\
\hline & $(0.0786)$ & $(0.172)$ & $(0.162)$ & $(0.162)$ \\
\hline \multirow{2}{*}{ Resolution $_{t-1}$} & $4.206^{* * *}$ & $3.598^{* * *}$ & $3.449^{* * *}$ & $3.644^{* * *}$ \\
\hline & $(0.266)$ & $(0.358)$ & $(0.371)$ & $(0.340)$ \\
\hline \multirow{2}{*}{ Constant } & $-3.168^{* * *}$ & $-3.030^{* * *}$ & $-2.759^{* * * *}$ & $-3.000^{* * *}$ \\
\hline & $(0.354)$ & $(0.420)$ & $(0.452)$ & $(0.400)$ \\
\hline$N$ & 1621 & 1040 & 893 & 1032 \\
\hline Pseudo. $R^{2}$ & 0.654 & 0.630 & 0.633 & 0.624 \\
\hline Chi Square & $353.76 * * *$ & $217.00 * * *$ & $171.69 * * *$ & $204.28 * * *$ \\
\hline Il & -242.61 & -167.14 & -149.64 & -169.29 \\
\hline AIC & 503.2 & 354.3 & 319.3 & 358.6 \\
\hline BIC & 551.7 & 403.8 & 367.2 & 408.0 \\
\hline
\end{tabular}


these two, penalized-likelihood criteria suggest that the most parsimonious models are those that include the sexual violence variables. ${ }^{10}$

Furthermore, four out of six models presented in Tables 1 and 2 suggest that the presence of sexual violence in a conflict increases the likelihood of resolutions while controlling for civilian battle deaths, rebel and government battle deaths, the cumulative intensity of the conflict, the duration of the conflict, P-5 ties to the conflict state, the prior establishment of UN personnel in the conflict and a resolution in the prior year. ${ }^{11}$ While the coefficients presented in Tables 1 and 2 are interesting, to better understand the substantive impact of key variables, it is important to also estimate the predicted probabilities of the likelihood of UN resolutions. Based on our estimations from Model 2 (Table 2, we first examine a "most likely case-scenario" for UNSC resolutions with the presence of UN peacekeepers, a cumulative intensity of over 1000 battle deaths, and a prior resolution on the civil conflict (with all other variables set at their mean values). When peacekeepers have been deployed, the presence of sexual violence has relatively little impact on the predicted probabilities of resolutions with the probability of a resolution ranging from 0.73 for no sexual violence to 0.81 for the highest level of sexual violence. Since one might expect the UN to be predisposed towards addressing a conflict in a year after it has deployed forces to the arena, it is perhaps not surprising that the highest levels of sexual violence raise the probability of a resolution by less than $10 \% .^{12}$

Figure 1, in contrast, presents the predicted probabilities for conflicts where the cumulative intensity of the conflict has not yet reached 1000 battle deaths and there is no established UN peacekeeping presence. Under this, less favourable scenario, sexual

\footnotetext{
${ }^{10}$ In Table 1 (with a reduced number of observations) the addition State Department and Human Rights Watch Sexual Violence variables (but not the Amnesty International variable) is preferable to the base model

11 These variables have been shown to be important determinants of UNSC activity in conflicts in general (Beardsley and Schmidt 2012, Benson and Satana 2008).

12 The graph of these predicted probabilities is presented in Appendix A4.
} 


\section{Figure 1}

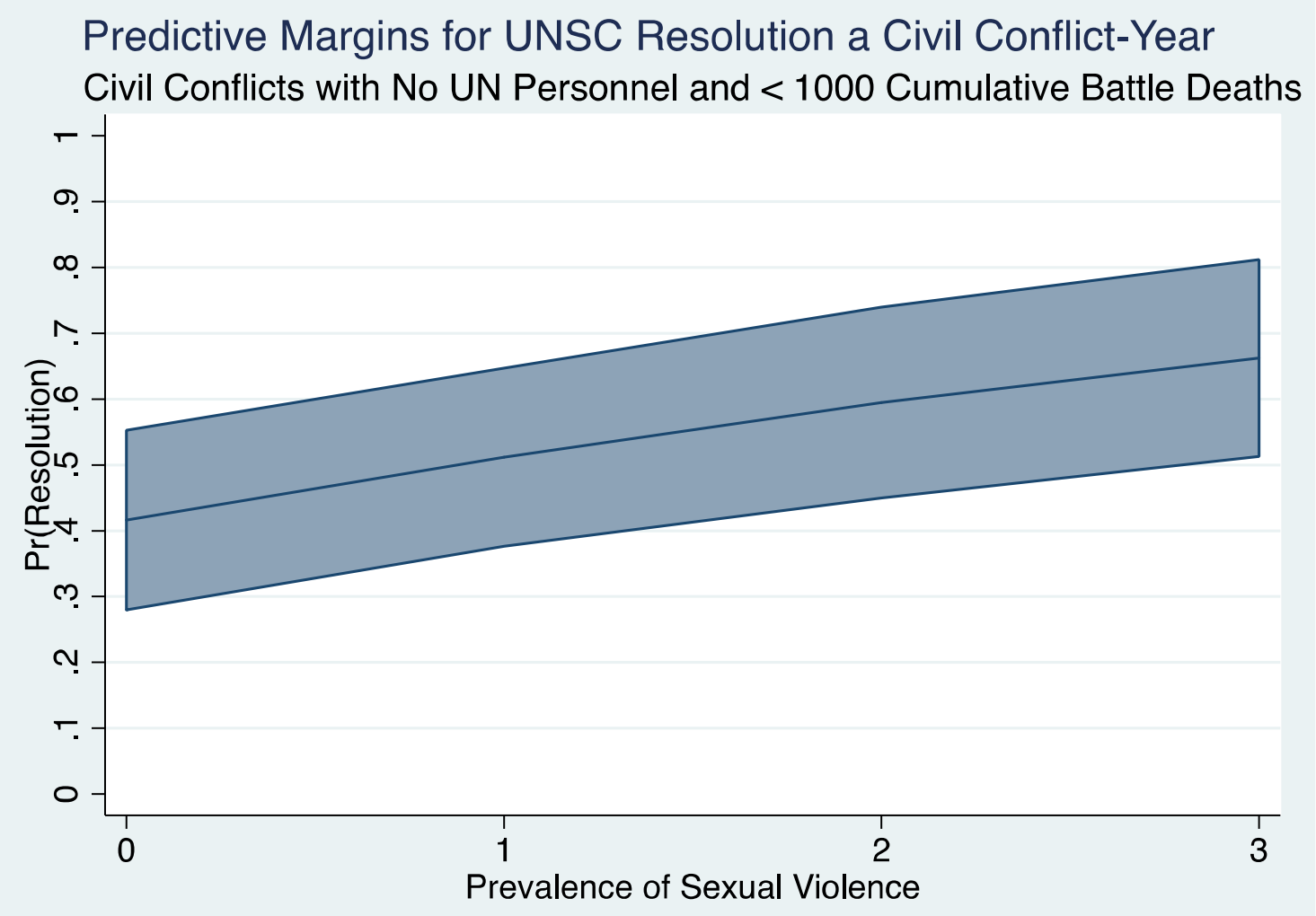

violence has a much more important effect. When there are no reports of sexual violence the probability of a UNSC resolution in the civil-conflict year is a much lower, $42 \%$. However, this probability jumps to $66 \%$ when there is systemic sexual violence. This $57 \%$ increase in the likelihood of a UNSC resolution suggests that sexual violence can have an impact in determining UN attention despite the absence of other important conflict factors.

The largest and most significant effects on the predicted likelihood of UNSC conflict resolutions occur with the highest level of sexual violence versus lower or no levels of sexual violence. As such we estimate a logit and associated predicted probabilities of the highest versus all other levels of sexual violence. We present these results below in Table 3. Holding independent variables at set values ${ }^{13}$, the presence of massive levels of sexual

\footnotetext{
13 Probabilities calculated for the presence of UN troops, over 1000 battle deaths, prior resolution, after passage of UNSC resolution 1325, non-P5 colony, and one year prior conflict duration. All other variables set at mean values.
} 
violence increase the predicted probability of a UNSC conflict resolution by $265 \%$ (from $17 \%$ to $62 \%$ ) and is significant at the $p=0.06$ level. The presence of the highest level of sexual violence likewise appears to have an interactive effect on the impact of the presence of UN troops and the cumulative intensity of conflicts on the presence of UNSC resolutions. At the highest level of sexual violence, conflict years with UN troops have a $182 \%$ higher probability of a UNSC conflict resolutions. However, when massive levels of sexual violence are not present the is no longer statistically significant. Similarly, conflicts with massive sexual violence that have surpassed the cumulative-intensity level of 1000 battle deaths are 55\% more likely to receive UNSC resolutions. When massive levels of sexual violence are absent, however, passing the cumulative intensity level no longer has a significant effect on changing the predicted probabilities of conflict resolutions. In short, the presence of massive levels of sexual violence, ceteris paribus, is associated with important increases in the likelihood of UNSC resolutions on a conflict. Importantly, the impact of sexual violence does not disappear in the presence other attributes that should be likely to push the UN towards resolutions (i.e., high numbers of battle deaths and the presence of UN troops). Furthermore, the absence of massive levels of sexual violence seem to reduce the impact of other important determinants of UNSC resolutions. 
Table 3: Predicted Probabilities of UNSC Conflict Resolution

\begin{tabular}{|l|c|c|c|}
\hline \multicolumn{1}{|c|}{\begin{tabular}{c}
\multicolumn{1}{c|}{ Variable } \\
Change
\end{tabular}} & $\begin{array}{c}\text { Predicted } \\
\text { Probability Levels }\end{array}$ & $\begin{array}{c}\text { Probability } \\
\text { Change }\end{array}$ & $\begin{array}{c}\text { Significance of } \\
\text { Probability Change* }\end{array}$ \\
\hline \hline $\begin{array}{l}\text { Sexual Violence: } \\
\text { Non-Massive } \rightarrow \text { Massive }\end{array}$ & $0.17 \rightarrow 0.62$ & $+265 \%$ & $\begin{array}{l}p=0.06 \\
94 \% \text { CI: } 0.003-0.90\end{array}$ \\
\hline $\begin{array}{l}\text { UN Troops with } \\
\text { Massive Sexual Violence } \\
\text { No UN Troops } \rightarrow \text { UN } \\
\text { Troops }\end{array}$ & $0.22 \rightarrow 0.62$ & $+182 \%$ & $\begin{array}{l}p=0.01 \\
99 \% \text { CI: } 0.077-0.71\end{array}$ \\
\hline $\begin{array}{l}\text { UN Troops with } \\
\text { Non-Massive Sexual Viol. }\end{array}$ & $0.03 \rightarrow 0.17$ & n.s. & n.s.at $p=0.10$ \\
$\begin{array}{l}\text { No UN Troops } \rightarrow \text { UN } \\
\text { Troops }\end{array}$ & $0.40 \rightarrow 0.62$ & $+55 \%$ & $\begin{array}{l}p=0.02 \\
98 \% \text { CI: } 0.02-0.42\end{array}$ \\
\hline $\begin{array}{l}\text { Cumulative Intensity with } \\
\text { Massive Sexual Viol. } \\
\text { Under } \rightarrow \text { Over 1000 Cum } \\
\text { Battle Deaths }\end{array}$ & $0.07 \rightarrow 0.17$ & n.s. & $n . s$. at $p=0.10$ \\
\hline $\begin{array}{l}\text { Cumulative Intensity with } \\
\text { Non-Massive Sexual Viol. } \\
\text { Under } \rightarrow \text { Over 1000 Cum } \\
\text { Battle Deaths }\end{array}$ & & & \\
\hline
\end{tabular}

*Confidence Intervals for Change in Predicted Probabilities calculated by the Delta Method in Stata 14.2.

Of course, while any attention by the UNSC is an important preliminary step in the quest for international action, one could reasonably argue that consistent and high-level attention by the UN is a more reliable marker of consensus on the Security Council. As such, the following four tables estimate the effects of the reported prevalence of sexual violence on the number of UNSC resolutions in a conflict-year, the highest level of recommended action in UNSC resolutions, and the number of high-level resolutions.

Tables 4 and 5 present the negative binomial estimations of the count of UNSC resolutions in a conflict-year. As above, Model 1 presents an estimation without the inclusion of our main theoretical independent variables. In Models 2 through 4 in Table 4, the Prevalence of Sexual Violence variables significantly and positively impact the number of UNSC resolutions for the State Department and Human Rights measures. While Civilian 
Deaths is positively associated with higher level of resolutions, as with Battle Deaths, their effects are not significant. Indeed, aside from past attention to the conflict by the UN in the form of a resolution in the prior year, prior establishment of troops or personnel, and conflict duration, the only significant variables that increase the rate of resolutions are the Sexual Violence variables. In Table 5, with an increase in number of conflict-years, all Sexual Violence variables all have a positive, highly significant $(p<=0.01)$ impact on the rate of resolutions and the Cumulative Intensity of deaths and former P5 colonial status once again obtain an expected significant relationship with the number of resolutions in a conflict-year.

The impact of the Prevalence of Sexual Violence on the level of UNSC resolutions and the count of high-level UNSC resolutions as presented in Tables 6 and 7 are similarly consistent. Indeed, sexual violence is shown to affect the intensity of UNSC resolutions positively and significantly in each of the 8 models in these two tables.

To better ascertain the effect of sexual violence on the highest level of recommended UNSC actions in a civil-conflict-year, in Figure 2 we present the predicted probabilities of different resolution levels using the same conditions as the logit analyses of the predicted presence of UNSC resolutions. As before, when we examine a theoretical "best-case" scenario for UNSC resolutions where there have been a high cumulative number of battle deaths and UN personnel are on the ground, the prevalence of sexual violence has little impact upon the likelihood of any level of action. While the first five levels of action (statement, demand, mediation, sanctions, and outside action) are all statistically 
Table 4

\begin{tabular}{|c|c|c|c|c|}
\hline \multicolumn{5}{|c|}{$\begin{array}{c}\text { Negative Binomial Logit: Count of UNSC Resolutions } \\
\text { in a Conflict-Year, 1990-2009 }\end{array}$} \\
\hline & Model 1 & Model 2 & Model 3 & Model 4 \\
\hline \multirow{2}{*}{$\begin{array}{l}\text { Sexual Violence } \\
\text { State Dept }\end{array}$} & & $0.273^{*}$ & & \\
\hline & & $(0.125)$ & & \\
\hline \multirow{2}{*}{$\begin{array}{l}\text { Sexual Violence } \\
\text { HRW }\end{array}$} & & & $0.312^{*+}$ & \\
\hline & & & $(0.139)$ & \\
\hline \multirow{2}{*}{$\begin{array}{l}\text { Sexual Violence } \\
\text { Amnesty Int }\end{array}$} & & & & $0.170^{*}$ \\
\hline & & & & $(0.0845)$ \\
\hline \multirow{2}{*}{ Civilian Deaths } & 0.542 & 0.533 & 0.436 & 0.533 \\
\hline & $(0.406)$ & $(0.349)$ & $(0.292)$ & $(0.3699)$ \\
\hline \multirow{2}{*}{ Battle Deaths } & -0.0704 & -0.0316 & 0.0892 & -0.0475 \\
\hline & $(0.359)$ & $(0.333)$ & $(0.327)$ & $(0.355)$ \\
\hline \multirow{2}{*}{ UN Personnel $t_{t-1}$} & $1.024^{* * *}$ & $0.962^{* * *}$ & $0.847^{* * *}$ & $0.986^{* * *}$ \\
\hline & $(0.223)$ & $(0.235)$ & $(0.216)$ & $(0.228)$ \\
\hline \multirow{2}{*}{$\begin{array}{l}\text { Cumulative } \\
\text { Intensity }\end{array}$} & 0.415 & 0.260 & 0.120 & 0.322 \\
\hline & $(0.309)$ & $(0.301)$ & $(0.310)$ & $(0.310)$ \\
\hline \multirow{2}{*}{ Conflict Duration t-1 } & $-0.0324^{* * *}$ & $-0.0305^{* * *}$ & $-0.0297^{* * * *}$ & $-0.0318^{* * * *}$ \\
\hline & $(0.00790)$ & $(0.00803)$ & $(0.00789)$ & $(0.00798)$ \\
\hline \multirow{2}{*}{ Resolution 1325} & 0.374 & 0.247 & 0.306 & 0.314 \\
\hline & $(0.223)$ & $(0.249)$ & $(0.222)$ & $(0.221)$ \\
\hline \multirow{2}{*}{ P5 Colony } & $-0.696^{* * *}$ & $-0.687^{* *}$ & $-0.644^{* *}$ & $-0.694^{* *}$ \\
\hline & $(0.182)$ & $(0.182)$ & $(0.179)$ & $(0.178)$ \\
\hline \multirow{2}{*}{ rGDPpc } & $-0.158^{+}$ & $-0.149^{+}$ & $-0.157^{+}$ & $-0.142^{+}$ \\
\hline & $(0.0946)$ & $(0.0845)$ & $(0.0897)$ & $(0.0823)$ \\
\hline \multirow{2}{*}{ Population } & -0.0187 & -0.0238 & -0.0210 & -0.0227 \\
\hline & $(0.0264)$ & $(0.0352)$ & $(0.0323)$ & $(0.0328)$ \\
\hline \multirow{2}{*}{ Resolution $_{t-1}$} & $2.509^{* * *}$ & $2.442^{* * *}$ & $2.381^{* * *}$ & $2.484^{* * * *}$ \\
\hline & $(0.244)$ & $(0.251)$ & $(0.239)$ & $(0.246)$ \\
\hline \multirow{2}{*}{ Constant } & $-1.378^{* *}$ & $-1.378^{* * * *}$ & $-1.145^{* *}$ & $-1.348^{* * *}$ \\
\hline & $(0.272)$ & $(0.279)$ & $(0.272)$ & $(0.271)$ \\
\hline$N$ & 715 & 707 & 627 & 708 \\
\hline Pseudo. $R^{2}$ & 0.289 & 0.297 & 0.295 & 0.291 \\
\hline Chi Square & $406.89 * * *$ & $492.72 * * *$ & $326.95 * * *$ & $421.95 * * *$ \\
\hline Il & -424.15 & -418.70 & -390.01 & -422.18 \\
\hline AIC & 872.3 & 863.4 & 806.0 & 870.4 \\
\hline BIC & 927.2 & 922.7 & 863.7 & 929.7 \\
\hline
\end{tabular}

Alphas significant at $\mathrm{p}<0.001$, Standard errors in parentheses, ${ }^{+} p<0.10,{ }^{*} p<0.05,{ }^{* *} p<0.01,{ }^{* * * *} p<0.001$ 
Table 5

Negative Binomial Logit: Count of UNSC Resolutions in a Conflict-Year, 1990-2009

\begin{tabular}{|c|c|c|c|c|}
\hline & Model 1 & Model 2 & Model 3 & Model 4 \\
\hline \multirow{2}{*}{$\begin{array}{l}\text { Sexual Violence } \\
\text { State Dept }\end{array}$} & & $0.286^{* *}$ & & \\
\hline & & $(0.105)$ & & \\
\hline \multirow{2}{*}{$\begin{array}{l}\text { Sexual Violence } \\
\text { HRW }\end{array}$} & & & $0.377^{* *}$ & \\
\hline & & & $(0.126)$ & \\
\hline \multirow{2}{*}{$\begin{array}{l}\text { Sexual Violence } \\
\text { Amnesty Int. }\end{array}$} & & & & $0.270^{* *}$ \\
\hline & & & & $(0.0826)$ \\
\hline \multirow{2}{*}{ UN Personnel $t_{t-1}$} & $0.899^{* * *}$ & $0.870^{* * *}$ & $0.734^{* * *}$ & $0.898^{* * * *}$ \\
\hline & $(0.153)$ & $(0.208)$ & $(0.197)$ & $(0.203)$ \\
\hline \multirow{2}{*}{$\begin{array}{l}\text { Cumulative } \\
\text { Intensity }\end{array}$} & $0.656^{* * *}$ & $0.671^{* * *}$ & $0.530^{* *}$ & $0.661^{* * *}$ \\
\hline & $(0.144)$ & $(0.185)$ & $(0.189)$ & $(0.191)$ \\
\hline \multirow{2}{*}{$\begin{array}{l}\text { Conflict Duration } \\
\text { t-1 }\end{array}$} & $-0.0236^{* * * *}$ & $-0.0311^{* * *}$ & $-0.0311^{* * * *}$ & $-0.0315^{* * *}$ \\
\hline & $(0.00491)$ & $(0.00701)$ & $(0.00668)$ & $(0.00696)$ \\
\hline \multirow{2}{*}{ Resolution 1325} & $0.458^{* *}$ & 0.273 & 0.310 & 0.316 \\
\hline & $(0.143)$ & $(0.189)$ & $(0.181)$ & $(0.176)$ \\
\hline \multirow{2}{*}{ P5 Colony } & $-0.613^{* * *}$ & $-0.609^{* * *}$ & $-0.546^{* *}$ & $-0.609^{* * *}$ \\
\hline & $(0.137)$ & $(0.169)$ & $(0.167)$ & $(0.167)$ \\
\hline \multirow{2}{*}{ rGDPpc } & $-0.288^{* *}$ & -0.191 & -0.201 & -0.178 \\
\hline & $(0.111)$ & $(0.106)$ & $(0.105)$ & $(0.0980)$ \\
\hline \multirow{2}{*}{ Population } & 0.00614 & -0.0160 & -0.0167 & -0.0171 \\
\hline & $(0.0132)$ & $(0.0245)$ & $(0.0290)$ & $(0.0253)$ \\
\hline \multirow{2}{*}{ Resolution $_{t-1}$} & $2.668^{* * *}$ & $2.544^{* * *}$ & $2.449^{* * *}$ & $2.587^{* * *}$ \\
\hline & $(0.201)$ & $(0.235)$ & $(0.222)$ & $(0.231)$ \\
\hline \multirow[t]{2}{*}{ Constant } & $-1.846^{* * * *}$ & $-1.776^{* * *}$ & $-1.495^{* * *}$ & $-1.738^{* * *}$ \\
\hline & $(0.198)$ & $(0.233)$ & $(0.230)$ & $(0.224)$ \\
\hline$N$ & 1621 & 1040 & 893 & 1032 \\
\hline Pseudo. $R^{2}$ & 0.324 & 0.309 & 0.307 & 0.305 \\
\hline Chi Square & $620.43 * * *$ & $493.21 * * *$ & $377.70 * * *$ & $481.50 * * *$ \\
\hline ll & -837.89 & -562.07 & -519.55 & -563.81 \\
\hline AIC & 1695.8 & 1146.1 & 1061.1 & 1149.6 \\
\hline BIC & 1749.7 & 1200.6 & 1113.9 & 1203.9 \\
\hline
\end{tabular}

Alphas significant at $\mathrm{p}<0.001$, Standard errors in parentheses, ${ }^{+} p<0.10,{ }^{*} p<0.05,{ }^{* *} p<0.01,{ }^{* * * *} p<0.001$ 
Table 6

Negative Binomial Logit: Count of High-Level UNSC Resolutions in a Conflict-Year, 1990-2009

\begin{tabular}{|c|c|c|c|c|}
\hline & Model 1 & Model 2 & Model 3 & Model 4 \\
\hline \multirow{2}{*}{$\begin{array}{l}\text { Sexual Violence } \\
\text { State Dept }\end{array}$} & & $0.392^{*}$ & & \\
\hline & & $(0.154)$ & & \\
\hline \multirow{2}{*}{$\begin{array}{l}\text { Sexual Violence } \\
\text { HRW }\end{array}$} & & & $0.465^{* *}$ & \\
\hline & & & $(0.131)$ & \\
\hline \multirow{2}{*}{$\begin{array}{l}\text { Sexual Violence } \\
\text { Amnesty Int }\end{array}$} & & & & $0.462^{* * *}$ \\
\hline & & & & $(0.105)$ \\
\hline \multirow{2}{*}{ Civilian Deaths } & $0.589 *$ & $0.606^{*}$ & $0.495^{*}$ & $0.605^{* * *}$ \\
\hline & $(0.251)$ & $(0.251)$ & $(0.225)$ & $(0.233)$ \\
\hline \multirow{2}{*}{ Battle Deaths } & -0.660 & -0.625 & -0.480 & -0.714 \\
\hline & $(0.560)$ & $(0.611)$ & $(0.576)$ & $(0.562)$ \\
\hline \multirow{2}{*}{ UN Personnel $_{t-1}$} & $1.238^{* * *}$ & $1.178^{* * *}$ & $0.861^{* *}$ & $1.132^{* * *}$ \\
\hline & $(0.292)$ & $(0.320)$ & $(0.276)$ & $(0.321)$ \\
\hline \multirow{2}{*}{$\begin{array}{l}\text { Cumulative } \\
\text { Intensity }\end{array}$} & $0.651^{+}$ & 0.428 & 0.278 & 0.430 \\
\hline & $(0.382)$ & $(0.407)$ & $(0.373)$ & $(0.391)$ \\
\hline \multirow{2}{*}{$\begin{array}{l}\text { Conflict Duration } \\
\text { t-1 }\end{array}$} & $-0.0693^{* * *}$ & $-0.0698^{* * *}$ & $-0.0661^{* * *}$ & $-0.0704^{* * *}$ \\
\hline & $(0.0102)$ & $(0.0110)$ & $(0.0103)$ & $(0.0115)$ \\
\hline \multirow{2}{*}{ Resolution 1325} & $-0.772^{* *}$ & $-0.661^{*}$ & $0.678^{*}$ & 0.636 \\
\hline & $(0.278)$ & $(0.306)$ & $(0.270)$ & $(0.287)$ \\
\hline \multirow{2}{*}{ P5 Colony } & $-0.674^{* *}$ & $-0.734^{* *}$ & $-0.693^{* *}$ & $-0.734^{* *}$ \\
\hline & $(0.248)$ & $(0.262)$ & $(0.249)$ & $(0.252)$ \\
\hline \multirow{2}{*}{ rGDPpc } & -0.254 & -0.251 & -0.287 & -0.231 \\
\hline & $(0.229)$ & $(0.216)$ & $(0.251)$ & $(0.193)$ \\
\hline \multirow{2}{*}{ Population } & 0.00951 & 0.00880 & 0.0162 & 0.00729 \\
\hline & $(0.0239)$ & $(0.0213)$ & $(0.0262)$ & $(0.0187)$ \\
\hline \multirow{2}{*}{ Resolution $_{t-1}$} & $1.755^{* * *}$ & $1.595^{* * *}$ & $1.524^{* * * *}$ & $1.611^{* * * *}$ \\
\hline & $(0.287)$ & $(0.314)$ & $(0.314)$ & $(0.312)$ \\
\hline \multirow[t]{2}{*}{ Constant } & $-1.965^{* * *}$ & $-1.921^{* * *}$ & $-1.588^{* * *}$ & $-1.856^{* * *}$ \\
\hline & $(0.349)$ & $(0.347)$ & $(0.331)$ & $(0.332)$ \\
\hline$N$ & 715 & 707 & 627 & 708 \\
\hline Pseudo. $R^{2}$ & 0.310 & 0.327 & 0.336 & 0.330 \\
\hline Chi Square & $202.27 * * *$ & $229.20 * * *$ & $168.48 * * *$ & $192.17 * * *$ \\
\hline II & -201.70 & -196.32 & -184.87 & -195.42 \\
\hline AIC & 427.4 & 418.6 & 395.7 & 416.8 \\
\hline BIC & 482.3 & 477.9 & 435.5 & 476.2 \\
\hline
\end{tabular}

Alphas significant at $\mathrm{p}<0.001$, Standard errors in parentheses, ${ }^{+} p<0.10,{ }^{*} p<0.05,{ }^{* *} p<0.01,{ }^{* * *} p<0.001$ 
Table 7

Ordered Logit: Highest Level of UNSC Resolutions

in a Conflict-Year, 1990-2009

\begin{tabular}{|c|c|c|c|c|}
\hline & Model 1 & Model 2 & Model 3 & Model 4 \\
\hline \multirow{2}{*}{$\begin{array}{l}\text { Sexual Violence } \\
\text { State Dept }\end{array}$} & & $0.417^{* * *}$ & & \\
\hline & & $(0.159)$ & & \\
\hline \multirow{2}{*}{$\begin{array}{l}\text { Sexual Violence } \\
\text { HRW }\end{array}$} & & & $0.527^{*}$ & \\
\hline & & & $(0.212)$ & \\
\hline \multirow{2}{*}{$\begin{array}{l}\text { Sexual Violence } \\
\text { Amnesty Int }\end{array}$} & & & & $0.552^{* *}$ \\
\hline & & & & $(0.154)$ \\
\hline \multirow{2}{*}{ Civilian Deaths } & $0.474^{+}$ & $0.506^{+}$ & 0.388 & $0.525^{+}$ \\
\hline & $(0.276)$ & $(0.274)$ & $(0.258)$ & $(0.277)$ \\
\hline \multirow{2}{*}{ Battle Deaths } & -0.530 & -0.552 & -0.226 & -0.594 \\
\hline & $(0.584)$ & $(0.589)$ & $(0.525)$ & $(0.597)$ \\
\hline \multirow{2}{*}{ UN Personnel $t-1$} & $1.470^{* * *}$ & $1.451^{* * *}$ & $1.419^{* * *}$ & $1.525^{* * *}$ \\
\hline & $(0.344)$ & $(0.368)$ & $(0.349)$ & $(0.367)$ \\
\hline \multirow{2}{*}{$\begin{array}{l}\text { Cumulative } \\
\text { Intensity }\end{array}$} & 0.471 & 0.314 & -0.0314 & 0.296 \\
\hline & $(0.430)$ & $(0.438)$ & $(0.493)$ & $(0.453)$ \\
\hline \multirow{2}{*}{$\begin{array}{l}\text { Conflict Duration } \\
\text { t-1 }\end{array}$} & $-0.0301^{*}$ & $-0.0283^{*}$ & $-0.0251^{+}$ & $-0.0285^{*}$ \\
\hline & $(0.0131)$ & $(0.0133)$ & $(0.0140)$ & $(0.0132)$ \\
\hline \multirow{2}{*}{ Resolution 1325} & 0.413 & 0.256 & 0.268 & 0.264 \\
\hline & $(0.430)$ & $(0.438)$ & $(0.493)$ & $(0.453)$ \\
\hline \multirow{2}{*}{ P5 Colony } & $-0.573^{*}$ & $-0.597 *$ & $-0.537^{+}$ & $-0.592 *$ \\
\hline & $(0.284)$ & $(0.282)$ & $(0.306)$ & $(0.288)$ \\
\hline \multirow{2}{*}{ rGDPpc } & $-0.278^{+}$ & -0.247 & -0.253 & -0.204 \\
\hline & $(0.160)$ & $(0.152)$ & $(0.155)$ & $(0.129)$ \\
\hline \multirow{2}{*}{ Population } & -0.149 & -0.157 & -0.164 & -0.159 \\
\hline & $(0.135)$ & $(0.140)$ & $(0.139)$ & $(0.138)$ \\
\hline \multirow{2}{*}{ Resolution $_{t-1}$} & $2.971^{* * *}$ & $2.954^{* * *}$ & $2.769^{* * *}$ & $3.023^{* * *}$ \\
\hline & $(0.465)$ & $(0.468)$ & $(0.489)$ & $(0.474)$ \\
\hline \multirow{2}{*}{ Constant } & $1.688^{* * *}$ & $1.769^{* * *}$ & $1.377^{* * *}$ & $1.810^{* * *}$ \\
\hline & $(0.400)$ & $(0.407)$ & $(0.445)$ & $(0.404)$ \\
\hline$N$ & 715 & 707 & 2627 & 708 \\
\hline Pseudo. $R^{2}$ & 0.365 & 0.371 & 0.378 & 0.374 \\
\hline Chi Square & $213.43 * * *$ & $216.56^{* * * *}$ & $182.11 * * *$ & $225.39 * * *$ \\
\hline ll & -325.61 & -321.62 & -291.55 & -319.97 \\
\hline AIC & 683.2 & 677.2 & 617.1 & 673.9 \\
\hline BIC & 756.4 & 754.8 & 692.6 & 751.5 \\
\hline
\end{tabular}

Standard errors in parentheses, ${ }^{+} p<0.10,{ }^{*} p<0.05,{ }^{* *} p<0.01,{ }^{* * *} p<0.001$ 
significantly distinct from no action, they are not always distinct from one another and the individual predicted probabilities are quite low (see Appendix, Figure A5 for civil conflicts with UN personnel and less than 1000 cumulative deaths).

\section{Figure 2}

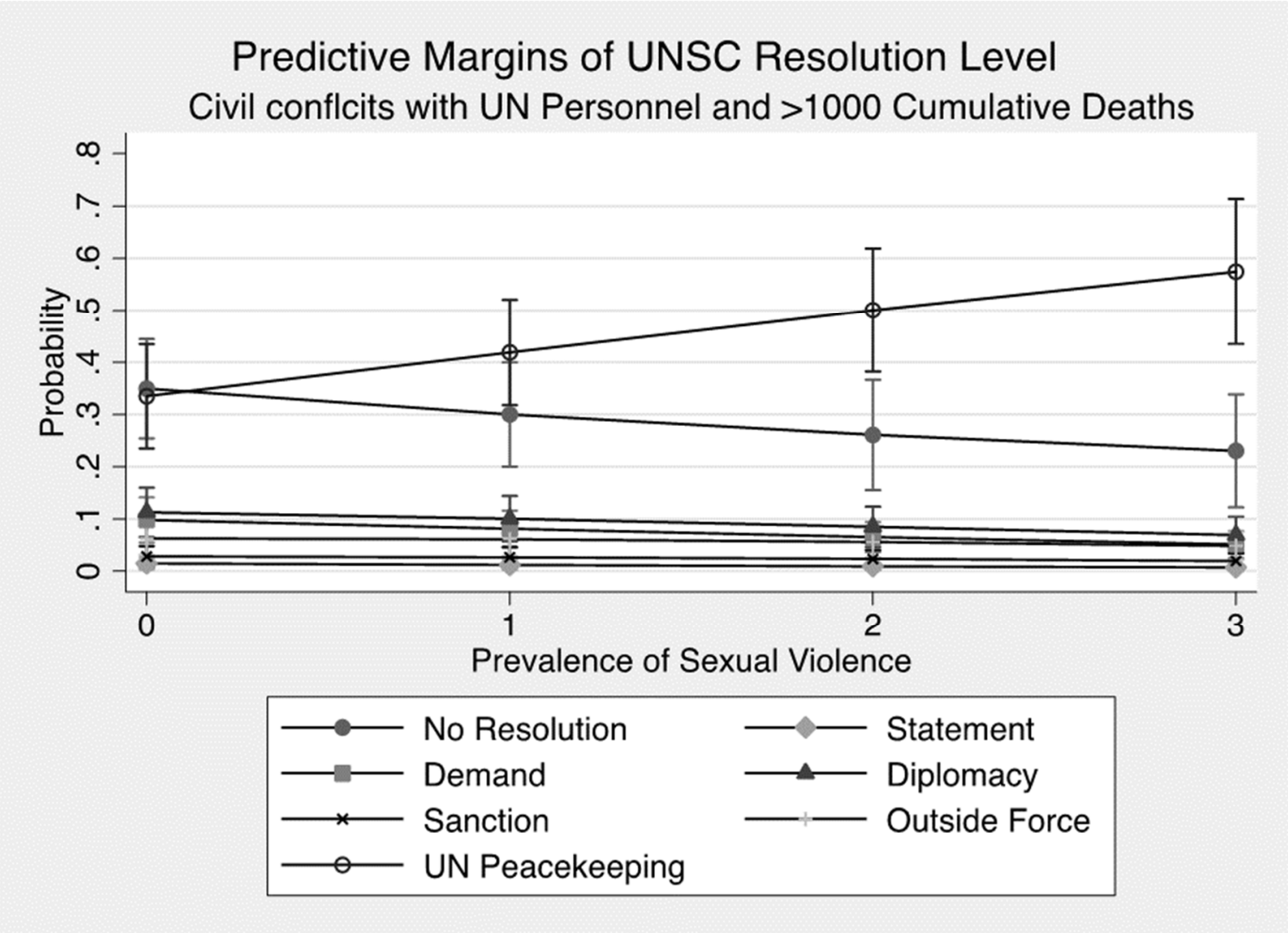

The aggregate predicted probability of a UNSC resolution short of peacekeeping is approximately $15 \%$ when there is systemic sexual violence (level 3). The predicted probability of peacekeeping resolutions, is significantly different from zero when sexual violence is widespread and systemic (levels 2 and 3). When sexual violence is presence at its highest levels, the predicted probability of a peacekeeping resolution is $0.57 \%$. Thus, sexual violence may have an important impact on UN conflict responses by pushing UNSC 
resolutions to higher levels of resolution outcomes above and beyond concurrent factors pushing the UN towards such actions.

Under less favourable conditions, the presence of sexual violence has a lower absolute but still positive impact upon the level of resolutions. At higher levels of sexual violence, UNSC resolutions short of peacekeeping are significantly different than the predicted probability for no resolution. Only the lowest levels of the prevalence of sexual violence, however, have an impact on the predicted probabilities of peacekeeping resolutions.

We further estimate the impact of different levels of sexual violence on different levels of the ordered logit dependent variable (i.e., no resolution, demand, diplomacy, sanction or siege, establishment or expansion of outside or regional IGO use of force, establishment or expansion of UN Peacekeeping operation) in Table 8, below. ${ }^{14}$ The largest effects of the prevalence of sexual violence are on the predicted probabilities of the absence of a UNSC resolution on a conflict. The likelihood of no UNSC resolution drops significantly when moving from no sexual violence to all other levels of sexual violence. Not surprisingly, the largest absolute effects (i.e., a decrease of $65 \%$ to $29 \%$ in the predicted probability of no resolution) is observed when comparing the effects of no sexual violence to massive reports of sexual violence. As regards the absolute probabilities of diplomacy, sanction or siege, or the approval or expansion of the outside use of force by regional IGOs or another state-level conflict actors, the likelihood is always quite low given the limited base probability of such UNSC resolutions. However, the impact of higher levels of sexual violence on the percent change in predicted probabilities of higher levers of UNSC resolutions is quite important, ranging from a $40 \%$ to a $200 \%$ increase in the likelihood of a

\footnotetext{
${ }^{14}$ We employ the same base settings for the independent variables as employed in the predicted probabilities for logits, above.
} 
Table 8: Predicted Probabilities of Level of UNSC Conflict Resolution

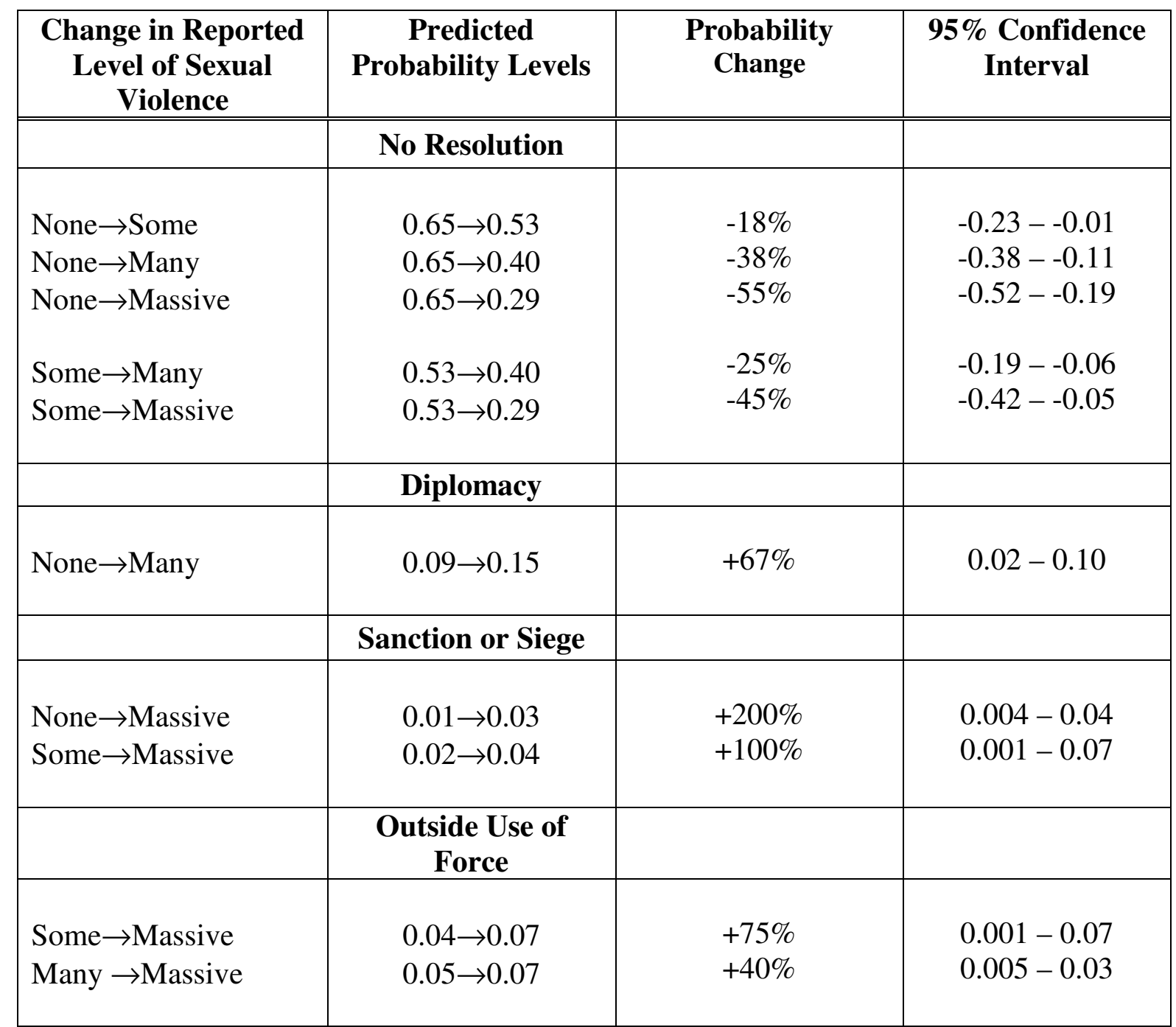

**Confidence Intervals for Change in Predicted Probabilities calculated by the Delta Method in Stata 14.2.

resolution. As such, we suggest, that any impact on the probability of an increased level UN response in civil conflicts is meaningful.

Higher levels of sexual violence, however, do not have a significant effect on UNSC resolutions in which the highest level is to simply state a demand or on the level of resolutions establishing/expanding of UN peacekeeping operations. Despite the lack of a significant impact on this highest level of UNSC resolutions, it is important to note that the results presented in Table 8 in conjunction with those presented in Tables 1-7 above and their associated predicted probabilities, provide important support for the generalized hypotheses 
that the presence and higher levels of sexual violence significantly increases UN attention and higher levels of response to civil conflicts.

To ensure that our models were robust to a variety of specifications we also included controls for the calendar year to ensure that that a potential increase in reporting of sexual violence over time was not responsible for the generally statistically significant relationship between our primary independent and dependent variables. The year variable was only significant in two of the base models and in none of the models which included sexual violence (i.e., 2 out of the 36 models in Tables 1-7 and A1-A2). Inclusion of the year variable never had a substantive effect on the size or significance of the sexual violence variable. We additionally estimated all models with the absolute number of troops rather than a dummy variable for troop presence. This operationalization of the presence of UN peacekeeping troops had no substantive effect on our results. ${ }^{15}$

\section{Conclusions}

In summary, our study provides empirical support for a gendered imperative in UNSC responses to civil conflicts. Taken together, the results suggest that sexual violence has a significant, independent impact on driving the UN towards action in civil conflicts. This impact can be seen even when there are other important factors, such as a high cumulative intensity of deaths and the prior establishment of UN troops in a conflict.

\footnotetext{
${ }^{15}$ We also ran each of models while lagging these four variables. The results are similar to those presented in the tables for the deaths variables with Civilian Deaths obtaining significance in $25 \%$ of models. For Battle Deaths, there is significance in $19 \%$ of models and UN Personnel obtains significance for $33 \%$ of models. For the Level of Sexual Violence variables there is significance for one of the variables in $25 \%$ of full models and in $38 \%$ of all models. Thus, in the lagged models, Sexual Violence performs at least as well or better than traditional casualty variables in predicting UNSC resolutions and performs better than the UN personnel variable which is also present in all models (38\% versus 33\%). We follow the same approach as prior work on the impact of temporally aggregate contemporaneous variables on UNSC resolutions and actions for international crises (Beardsley and Schmidt 2012).
} 
In short, the results presented here suggest that the UN Security Council is, at the least, implicitly attentive to sexual violence in conflicts. Sexual violence appears to affect the likelihood of both the presence and frequency of resolutions regarding a specific conflict. This is the case both when our models are estimated with a more limited sample controlling for civilian deaths and when the largest sample of civil conflict-years is employed. Thus, one might suggest that sexual violence is an important conflict "attribute" just as war duration, civilian deaths, or conflict intensity have been shown to be in prior literature on UNSC Resolutions.

The significant impact of three different measures of reported sexual violence on the presence, level, and number of high-level UNSC resolutions further suggests that the UN's limited explicit discussion of sexual violence within its resolutions does not represent a lack of UN response to the phenomenon. After the passage of UNSCR 1325, the long delay of adding language on sexual violence in subsequent resolutions and the relative paucity of resolutions that mention sexual violence, are not indicative of an absence of impact of sexual violence on the UN's attention to civil conflicts.

In fact, the passage of UNSCR1325 in 2000 was not a watershed moment, but rather the amalgamation of the continuous efforts of a decade of civil society organizations activism to raise awareness on the devastating effect of sexual violence on civilians during and after violent armed conflicts. Given that two out of the three of the measures of the reporting of sexual violence employed here are based upon Human Rights Watch and Amnesty International reports, our results also point to the importance of independent NGO assessments of conflict attributes in civil wars. The essential role of government, NGOs and other civil society organizations in bringing attention to crimes against civilians has been hinted at in the literature that examines one-sided violence in civil wars. Meernick et al. 
2012) show that higher numbers of human rights organizations in countries increase the reporting and urgent actions and campaigns by Amnesty International.

Our study is not without limitations. The analysis does not address whether the UN is capable or willing to impact levels of sexual violence within civil conflict. Feminist research has even argued that the UN cannot be used to increase women's and civilians' security, since peacekeeping remains a tool of militarization rather than a genuine alternative to war (for example, see Shepherd 2016; Tryggestad 2009; Whitworth 2004). Susan Willett (2010) even argues that the power inequalities within the UN tend to overshadow the gender discourse and to submerge it under the hierarchical patriarchal structures and militarist values of the organization without prospects for promoting genuine changes in the structures that generate violence against women.

Our findings raise concerns about unintended consequences that we cannot explore in this paper, but are important to reflect upon. A key concern in feminist research is the political consequences of what is measured and who provides information. The SVAC dataset has significant limitations in capturing different forms of sexual violence because of the original sources it uses. The framing of sexual violence by international organizations and agencies tends to conflate sexual violence against women with "gender-based violence" contributing to the marginalization of male victims of sexual violence (Charman 2018). The lack of engagement with male victims by non-governmental organizations contributes to the under-reporting of sexual violence, a major challenge for scholars and policymakers alike (Shivakumaran 2007).

Focusing on women as victims of rape raises questions of whether groups often engage in specific forms of violence that draw attention to the conflict and their demands by international actors. The recent use of extreme violence to influence an international audience by the Islamist State of Iraq and Syria (ISIS or ISIL) brings into question whether groups 
increasingly engage in sexual violence to generate a response by the UN or other international actors. Subsequently, sexual violence becomes more frequent for strategic reasons.

Fortunately, currently, there is no evidence that this is the case. Our cases suggest that UN response does not lead to high levels of sexual violence. The existing literature on sexual violence in armed conflicts suggests that most cases of sexual violence are the outcome of the failures of structure and command within fighting parties rather than a strategic choice. Incidents of rape while widespread, primarily fall under the principle-agent framework with breakdowns of order and organizational capacity as the leading reason behind the use of rape. In fact, most cases of sexual violence have been random rather than strategic. Often government forces, rather than rebel groups, are the main perpetrators of sexual violence (Baaz and Stern 2013; Cohen, Green, and Wood 2013; Nordäs 2011). The potential ad-hoc use of such violence in conflict, however, in no way mitigates its impact on populations in civil wars. Future research might want to explore the implications for advocacy of how sexual violence is framed, often essentialized, by non-governmental organizations and policymakers alike.

As with prior work, our paper corroborates that the UNSC members are responsive to attributes of violent conflicts (Beardsley and Schmidt 2012; Benson and Satana 2008) such as large numbers of battle deaths. However, we expand upon this research in illustrating that sexual violence is an additional, significant, attribute of violent armed conflicts as perceived by the UN. Importantly, the impact of sexual violence is shown to be independent of the process of UNSCR 1325. We thus suggest that conflict attributes, such as sexual violence, have a consequential impact on UNSC resolutions (the pre-coursers to UN action) even when no explicit mention is made of the conflict attribute in the resolutions themselves. 


\section{References:}

Alison, M. (2007). Wartime sexual violence: women's human rights and questions of masculinity. Review of International Studies, 33(01), 75-90.

Allen, B. (1996). Rape warfare: The hidden genocide in Bosnia-Herzegovina and Croatia. U of Minnesota Press.

Andersson, A. (2000). Democracies and UN peacekeeping operations, 1990-1996. International Peacekeeping, 7(2), 1-22.

Anderson, L. (2010). Politics by Other Means: When does Sexual Violence Threaten International Peace and Security?. International Peacekeeping, 17(2), 244-260.

Baaz, M. E., \& Stern, M. (2013). Sexual violence as a weapon of war?: Perceptions, prescriptions, Problems in the Congo and beyond. Zed Books.

Beardsley, K., \& Schmidt, H. (2012). Following the flag or following the charter? Examining the determinants of UN involvement in international crises, 1945-20021. International Studies Quarterly, 56(1), 33-49.

Bellamy, A. J. (2009). Responsibility to protect. Polity.

Benson, M. and Satana, N. 2008. "Choosing Sides: UN Resolutions and Non-Neutrality in International Conflicts.” in Jacob Bercovitch and Scott Gartner, eds. International Conflict Mediation: New Approaches and Findings. Routledge Press.

Benson, M., \& Kathman, J. D. (2014). United Nations Bias and Force Commitments in Civil Conflicts. The Journal of Politics, 76(02), 350-363. 
Berthou A. and Ehrhart H. (2017). Trade networks and colonial trade spillovers. Review of International Econonmics. 25 (891-923).

Binder, C., Lukas, K., \& Schweiger, R. (2008). Empty words or real achievement? The impact of Security Council Resolution 1325 on women in armed conflicts. Radical History Review, 2008(101), 22-41.

Bos, P. R. (2006). Feminists Interpreting the Politics of Wartime Rape: Berlin, 1945; Yugoslavia, 1992-1993. Signs, 31(4), 995-1025.

Brownmiller, S. (2013). Against our will: Men, women and rape. Open Road Media.

Carey, H. F. (2001). 'Women and peace and security': The politics of implementing gender sensitivity norms in peacekeeping. International Peacekeeping, 8(2), 49-68.

Carter, T. A. (2007). United Nations intervention decisions: a strategic examination. Work. Pap., Dep. Polit. Sci., Wayne State Univ.

Charman, T., (2018). Sexual violence or torture? In Zalewski, M., Drumond, P., Prugl, E., \& Stern, M. (eds.). Sexual violence against men in global politics. Routledge, 198-2011.

Sexual Violence Against Men in Global Politics

Cohen, D. K., Green, A. H., \& Wood, E. J. (2013). Wartime sexual violence:

Misconceptions, implications, and ways forward. Washington, DC: United States Institute of Peace.

Cohen, D. K. (2013). Explaining rape during civil war: Cross-national evidence (1980-2009). American Political Science Review, 107(03), 461-477.

Cohen, D.K., A. H. Green, and E.J. Wood. (2013). Wartime Sexual Violence 
Misconceptions, Implications, and Ways Forward. USIP Special Report 323, USIP. http://www.usip.org/sites/default/files/resources/SR323.pdf. (Accessed on 19-10-2016).

Cohen, D. K. and R. Nordås. (2014). Sexual Violence in Armed Conflict: A new dataset 1989-2009. Journal of Peace Research 51(3): 418-428.

Cohen, D. K. and R. Nordås. (2013). Sexual Violence in Armed Conflict (SVAC) Dataset Codebook and User Instruction Guide; http://www.sexualviolencedata.org/wpcontent/uploads/2013/01/SVAC-coding-manual-10-25-13.pdf (Accessed on 14/02/2017).

Cohen, D.K., R. Nordås and E. Wood. (2014). Four things everyone should know about wartime sexual violence, Washington Post - Monkey Cage. https://www.washingtonpost.com/news/monkey-cage/wp/2014/06/09/four-things-everyoneshould-know-about-wartime-sexual-violence/ (Accessed on 19-10-2016).

Cohn, C., Kinsella, H., \& Gibbings, S. (2004). Women, Peace and Security Resolution 1325. International Feminist Journal of Politics, 6(1), 130-140.

Croicu, Mihai, \& Ralph Sundberg (2012), UCDP GED Conflict Polygons dataset version 1.12011, UCDP, Department of Peace and Conflict Research, Uppsala University.

Fortna, V. P. (2004). Does peacekeeping keep peace? International intervention and the duration of peace after civil war. International studies quarterly, 48(2), 269-292.

Fortna, V. P. (2008). Does peacekeeping work?: shaping belligerents' choices after civil war. Princeton University Press.

Enloe, C. (2000). Maneuvers: The International Politics of Militarizing Women's Lives. Berkeley: University of California Press. 
Enloe, C. (2002). Demilitarization-or more of the same? Feminist questions to ask in the postwar moment. The Postwar Moment: Militaries, Masculinities and International Peacekeeping. London: Lawrence and Wishart.

Eisenstein, Z. R. (2007). Sexual decoys: Gender, race and war in imperial democracy. Spinifex Press.

Evans, G., \& Sahnoun, M. (2002). The responsibility to protect. Foreign affairs, 99-110.

Gibbs, D. N. (1997) Is peacekeeping a new form of imperialism? International Peacekeeping $4(1): 122-28$.

Gilligan, M. and Stedman, S. J. (2003). Where Do the Peacekeepers Go? 1. International Studies Review, 5(4), 37-54.

Gleditsch, Kristian S. (2002). "Expanded Trade and GDP Data," Journal of Conflict Resolution 46: 712-24.

Hoover Green, A. (2011). Ph.D., Department of Political Science, Yale University, New Haven, CT. Dissertation: Repertoires of Violence Against Noncombatants: The Role of Armed Group Institutions and Ideologies.

Hultman, L., Kathman, J., \& Shannon, M. (2013). United Nations peacekeeping and civilian protection in civil war. American Journal of Political Science, 57(4), 875-891.

Hultman, L. (2013). UN peace operations and protection of civilians Cheap talk or norm implementation?. Journal of Peace Research, 50(1), 59-73.

Human Rights Watch. (2005). "Seeking Justice: The Prosecution of Sexual Violence in the Congo War" March 2005 Vol. 17, No. 1(A). 
Johansson, K. and Hultman, L. (N.D.) "UN Peacekeeping and Protection from Sexual Violence.” Journal of Conflict Resolution, forthcoming.

de Jonge Oudraat, C. (1996). The United Nations and internal conflict. CSIA Studies in International Security, 489-536.

Kathman, J. (2013). United Nations peacekeeping personnel commitments, 1990-2011. Conflict Management and Peace Science 30(5), 532-549.

Kelly, L. (2000). Wars Against Women: Sexual Violence, Sexual Politics and the Militarised State. In Jacobs, S. Ruth Jacobson, R., and Jen Marchbank, J. (eds): States of Conflict: Gender, Violence and Resistance, edited by Susie London: Palgrave Macmillan, 45-65.

Kuziemko, I., \& Werker, E. (2006). How much is a seat on the Security Council worth? Foreign aid and bribery at the United Nations. Journal of political economy, 114(5), 905-930.

Krause, J. (2015). Revisiting Protection from Conflict-Related Sexual Violence: Actors, Victims, and Power. In: Gizelis, T-I. and L. Olsson (eds): A Systematic Understanding of Gender, Peace and Security: Implementing UNSCR 1325. Routledge Studies in Peace and Conflict Resolution Series, 99-115.

Lacina, B. \& Gleditsch, N.P. (2005) Monitoring trends in global combat: A new dataset of battle deaths. European Journal of Population 21(2-3), 145-166.

Mackenzie, M. (2010). Securitizing sex? Towards a theory of the utility of wartime sexual violence. International Feminist Journal of Politics 12(2), 202-221.

Marks, Z. (2014). Sexual violence in Sierra Leone's civil war:'Virgination', rape, and marriage. African Affairs, 113(450), 67-87. 
Meernik, J., Aloisi, R., Sowell, M. and Nichols, A., (2012). The impact of human rights organizations on naming and shaming campaigns. Journal of Conflict Resolution, 56(2): 233256.

Meintjes, S., Turshen M. and Pillay, A. (2001). The aftermath: Women in post-conflict transformation. London: Zed books.

Meger, S. (2016). Rape Loot Pillage: The political economy of sexual violence in armed conflict. Oxford University Press.

Nordäs, R. (2011). Sexual Violence in African Conflicts, PRIO Policy Brief, 1. Oslo: PRIO. http://www.usip.org/sites/default/files/missing-peace/Ragnhild-Nordas.pdf (Accessed on 1910-2016).

Olsson, L. (2000). Mainstreaming gender in multidimensional peacekeeping: A field perspective. International Peacekeeping, 7(3), 1-16.

Olsson, L. (2009). Gender equality and United Nations peace operations in Timor Leste (Vol. 14). Brill.

Olsson, L., \& Gizelis, T. I. (2015). An introduction to Resolution 1325. Gender, Peace and Security: Implementing UN Security Council Resolution 1325, 1.

Olsson, L. Same Peace, Different Quality? The Importance of Security Equality for Quality Peace. Dimensions of Quality Peace, forthcoming.

Pankhurst, D. (2010). Sexual violence in war. Gender Matters in Global Politics: A Feminist Introduction to International Relations, , 148-160.

Ruggeri, A., Dorussen, H., and Gizelis, T,-I. (2016). n the frontline every day? Subnational deployment of United Nations peacekeepers. British Journal of Political Science, 1-21. 
Seifert, R. (1994). War and rape: A preliminary analysis. Mass rape: The war against women in Bosnia-Herzegovina, 54-72.

Seifert, R. (1996). The second front: The logic of sexual violence in wars. Women's Studies International Forum. 19(1-2), 35-43.

Shepherd, L. J. (2008). Power and authority in the production of United Nations Security Council Resolution 1325. International Studies Quarterly, 52(2), 383-404.

Shepherd, L. J. (2016). Making war safe for women? National Action Plans and the militarisation of the Women, Peace and Security agenda. International Political Science Review, 37(3), 324-335.

Sivakumaran, S. (2007). "Sexual violence against men in armed conflict.” European Journal of International Law 18(2): 253-276.

Sjoberg, L. (2013). Gendering global conflict: toward a feminist theory of war. Columbia University Press.

Skjelsbæk, I. (2001). Sexual violence in times of war: a new challenge for peace operations?. International Peacekeeping, 8(2), 69-84.

Skjelsbæk, I. (2010). The Elephant in the Room: An Overview of How Sexual Violence came to be seen as a Weapon of War.

Stahn, C. (2007). Responsibility to protect: political rhetoric or emerging legal norm. Am. J. Int'1 L., 101, 99.

Stojek, S. M., \& Tir, J. (2015). The supply side of United Nations peacekeeping operations: Trade ties and United Nations-led deployments to civil war states. European Journal of International Relations, 21(2), 352-376. 
ten Bensel, T., \& Sample, L. L. (2015). Collective Sexual Violence in Bosnia and Sierra Leone A Comparative Case Study Analysis. International journal of offender therapy and comparative criminology, $0306624 X 15609704$.

Tryggestad, T. L. (2009). Trick or Treat? The UN and Implementation of Security Council Resolution 1325 on Women, Peace, and Security. Global Governance: a review of multilateralism and international organizations, 15(4), 539-557.

UCDP Battle-Related Deaths Dataset v.5-2015, Uppsala Conflict Data Program, www.ucdp.uu.se, Uppsala University", and, when applicable, the UCDP Battle-Related Deaths Dataset.

Willett, S. (2010). Introduction: Security Council Resolution 1325: assessing the impact on women, peace and security. International Peacekeeping, 17(2), 142-158.

Whitworth, S. (2004). Men, militarism and UN peacekeeping: A Gendered Analysis, Boulder, CO: Lynne Rienner.

Wood, E. J. (2006). Variation in sexual violence during war. Politics \& Society, 34(3), 307342.

Wood, E. J. (2009). Armed groups and sexual violence: When is wartime rape rare?. Politics \& Society, 37(1), 131-161.

Zalewski, M., Drumond, P., Prugl, E., \& Stern, M. (Eds.). (2018). Sexual violence against men in global politics. Routledge. 